Maurizio Gotti

\title{
Explanatory strategies in university courses taught in ELF
}

Abstract: In the last few years many universities have internationalised their courses by offering them in English. Very often the lecturers remain the local ones, who adopt English as a means of instruction although they are not native speakers of that language. In many cases the teaching of such courses is assigned to foreign lecturers, who are not chosen specifically for their language competence but rather according to their expertise in the subject they are supposed to be teaching. As they are taught in English, these courses attract many students from other countries. The result is a typical ELF situation in which most lecturers and students - although they are not native speakers of English - use this language as a common means of communication and instruction.

The present paper examines communicative interactions taking place in such contexts. The data are taken from "international" courses on specialised disciplines offered by the University of Bergamo, recorded and transcribed according to the conventions adopted in the compilation of the ELFA Corpus (Mauranen et al. 2010). In particular, the first part of the paper examines the most common strategies employed by lecturers to explain the main specialised terms and technical concepts concerning the specific courses they are teaching, as well as those adopted to overcome the difficulties of comprehension experienced by their students. The second part of the paper takes into consideration the cooperative work carried out by both learners and teachers in the explanation/ comprehension of specific topics in order to facilitate the achievement of the teaching/learning objectives of the courses.

Keywords: explanatory activities, ELF, university courses, communicative strategies, cooperative work

\section{Strategie di spiegazione in corsi universitari insegnati in Inglese Lingua Franca}

Riassunto: In questi ultimi anni molte università hanno internazionalizzato i propri corsi offrendoli in inglese. Molto spesso i docenti rimangono quelli locali, che

Maurizio Gotti: Università di Bergamo. E-mail: m.gotti@unibg.it 
adottano l'inglese come mezzo di istruzione sebbene non siano parlanti nativi di quella lingua. In molti casi la titolarità di tali corsi viene assegnata a docenti stranieri, che non sono scelti principalmente per la loro competenza linguistica, ma piuttosto per la padronanza della materia che devono insegnare. Essendo insegnati in inglese, questi corsi attraggono molti studenti da altri paesi. Di conseguenza si verifica una situazione tipica dell'Inglese come Lingua Franca, in cui la maggior parte dei docenti e degli studenti - sebbene non siano parlanti nativi di inglese - usano questa lingua come mezzo comune di comunicazione e di istruzione.

Il presente articolo esamina interazioni comunicative che hanno luogo in tali contesti. I dati sono tratti da corsi 'internazionalizzati' di discipline specialistiche offerti dall'Università di Bergamo, registrati e trascritti secondo le convenzioni adottate nella compilazione del corpus ELFA (Mauranen et al. 2010). In particolare, la prima parte esamina le strategie più comunemente impiegate dai docenti per spiegare i principali termini specialistici e i concetti tecnici riguardanti i corsi specifici che vengono insegnati, così come quelle adottate per superare le difficoltà di comprensione incontrate dagli studenti. La seconda parte prende in considerazione gli sforzi comunicativi sia degli studenti che dei docenti nella spiegazione / comprensione di argomenti specifici al fine di facilitare il raggiungimento degli obiettivi didattici e di apprendimento dei corsi.

Parole chiave: attività di spiegazione, Inglese come Lingua Franca, corsi universitari, strategie comunicative, sforzo collaborativo

DOI 10.1515/jelf-2014-0020

\section{Introduction}

In the last few years many universities in countries outside the English-speaking circle have internationalised their courses by offering them in English. Very often the lecturers remain the local ones, who adopt English as a means of instruction although they are not native speakers of that language. In many cases the teaching of such courses is assigned to foreign lecturers, who are not chosen specifically for their language competence but rather according to their expertise in the subject they are supposed to be teaching. As they are taught in English, these courses attract many students from other countries. The result is a typical ELF situation in which most lecturers and students use this language as a common means of communication and instruction. 
Several studies have taken into consideration the use of ELF in EnglishMedium Instruction (EMI) courses organised by universities, some of them investigating formal aspects (Ranta 2006, 2009; Björkman 2008a, 2008b, 2009) while others focusing on pragmatic issues (Leznyák 2002; Mauranen 2003, 2006a, 2006b, 2012; Cogo 2009; Kaur 2009; Smit 2009; Suviniitty 2010; Smit and Dafouz 2012). As regards the latter, Mauranen (2003) has pointed out the adoption of "self-regulation" strategies, by means of which speakers tend to adapt their way of speaking to the interlocutors' assumed linguistic competence. Another strategy commonly employed is the recourse to "self-repairs," which takes place when words or expressions previously formulated are proposed in a different way by the same person to facilitate the hearers' comprehension. A further way to promote understanding is by means of "self-repetitions," which occur when the lecturer repeats something said before to make his concepts clearer (Mauranen 2006b). The clarification of meaning also implies the adoption of cooperative strategies and "interactive repairs" by both the speaker and the interlocutors whenever difficulties or non-understanding occurs. Hearers, in particular, recur to "minimal incomprehension signals" (Mauranen 2006b) or direct questions when they encounter comprehension problems. By means of "utterance completions" (Seidlhofer 2001) and “overlaps" (Cogo 2009) they manifest their willingness to cooperate in the fulfilment of the communicative act. Sometimes, however, minor points of non-comprehension are not raised by the interlocutor, who prefers to adopt a "let it pass" strategy (Firth 1996) in order not to create unnecessary breaks in the interactive flow, on the assumption that the unclear word or expression will either become clear or redundant as talk progresses.

The present paper examines communicative interactions taking place in such contexts. The main aim of our analysis is to investigate the strategies adopted by lecturers in their teaching activities as well as the cooperative work carried out by both learners and teachers. The data are taken from "international" courses on specialised disciplines offered by the University of Bergamo, recorded and transcribed according to the conventions adopted in the compilation of the ELFA Corpus (Mauranen et al. 2010). In particular, the first part of the paper examines the strategies employed by lecturers to explain the main specialised terms and technical concepts from the specific courses they are teaching, as well as those adopted to overcome the difficulties of comprehension experienced by their students. The second part of the paper takes into consideration the cooperative work carried out by both learners and teachers in the explanation/ comprehension of specific topics in order to facilitate the achievement of the teaching/learning objectives of the courses. 


\section{Material and methods}

The data examined in this paper are derived from three courses: Marketing Management, European Tourism Law, and Business Ethics and Social Accounting, offered by the University of Bergamo, taught by experts for whom English is not a native language and who come from countries where English is not a dominant official language, and attended by students from different lingua-cultural backgrounds. In particular, the corpus consists of the recordings of 21 hours of the Marketing Management course, 27 hours of European Tourism Law lessons, and 34 hours of Business Ethics and Social Accounting teaching activities. One lecturer came from Switzerland and was a German native speaker (although he also spoke French fluently); the other two were Italian (both also male), one of them, however, often teaching at a British university. There were 62 students attending the two courses. They came from 12 different countries: Albania (3), Australia (1), Bangladesh (2), Cameroon (1), China (3), France (1), Great Britain (3), Italy (28), Latvia (1), Mexico (2), Serbia (2), United States (15). The lectures were mainly monologic with the lecturers mostly talking to the students; only part of the lectures was interactive, with the students working in groups or presenting their own work.

The methodology employed for the analysis of the data is mainly qualitative and is based on selected pieces of the lectures recorded. As regards the investigation of the strategies employed by lecturers to explain the main specialised terms and technical concepts, particular attention was devoted to the examination of the metadiscursive strategies used. Indeed, in the context of academic lectures, a high degree of correlation has been established between the lecturers' efforts to make their lessons more accessible to their students' understanding and their use of metadiscursive strategies. It has been shown that the insertion of appropriate metadiscursive elements makes the comprehension of lectures easier, particularly to less proficient students. For this purpose Aguilar Pérez and Arnò Macià (2002) have summarised the strategies that according to their observations have proved more successful (cf. Table 1). Their classification is principally based on a functional, Hallidayan approach in that metadiscourse is divided into textual and interpersonal items, and draws on the main studies on metadiscourse published up to then (Crismore 1989; Mauranen 1993; Hyland 1998, 1999).

As regards the analysis of the cooperative strategies adopted by both learners and teachers in the achievement of the teaching/learning objectives of the courses, the interactions will mainly be examined from a CAT (Communication Accommodation Theory) perspective (Giles et al.1991; Giles and Ogay 2007), so as to identify the adjustments made by the interlocutors in order to favour mutual 
Table 1: A classification of metadiscursive elements (adapted from Aguilar Pérez and Arnò Macià 2002: 11).

\begin{tabular}{|c|c|}
\hline Category & Function \\
\hline \multicolumn{2}{|l|}{ Textual } \\
\hline Frame markers & Mark transitions between different stages \\
\hline Illocutionary markers & Name the act the speaker performs or announce the speaker's intention \\
\hline Reminders & Refer back to other sections of the lecture \\
\hline Attributors & Provide support for the speaker's arguments \\
\hline Code glosses & Clarify, explain, rephrase or exemplify propositional meaning \\
\hline \multicolumn{2}{|l|}{ Interpersonal } \\
\hline Certainty & Express full commitment to the statement \\
\hline Emphatics & Highlight aspects of propositional content or mark salience \\
\hline Attitude & Express the speaker's attitude towards propositional content \\
\hline Relational markers & Establish and maintain rapport with the audience \\
\hline Person markers & Explicitly refer to the speaker \\
\hline
\end{tabular}

intelligibility and successful linguistic communication. As Pennebaker et al. (2003) assert:

According to communication accommodation theory, individuals negotiate the social distance between themselves and their interacting partners, creating, maintaining, or decreasing that distance. This can be done linguistically, paralinguistically, and nonverbally. Specific accommodative strategies may include speech styles, speech rate, pitch, accent convergence, response latency, use of pauses, phonological variations, smiling, or gaze. (Pennebaker et al. 2003: 566)

In her analysis of the phonological aspects of ELF, Jenkins identifies four main socio-psychological tenets on which CAT is based:

[...] the theory of similarity attraction, which claims that people are more attracted to those who share similar beliefs and attitudes than to others. Secondly, social exchange theory, according to which people weigh up the rewards and costs of alternatives before they act. Thirdly, the theory of causal attribution, which suggests that people evaluate one another's behaviour according to their interpretation of the motives underlying that behaviour. Fourthly, intergroup distinctiveness, according to which people attempt to maintain their group identity by retaining their distinctiveness from other groups. (Jenkins 2000: 168, emphasis added)

This accommodation process requires even more complex strategies when interlocutors belong to various social backgrounds (Cai and Rodriguez 1997) as cultural values and implicit meanings may be different and not always known or 
shared by the interlocutors. The reliance on these socio-psychological aspects implies that accommodation is a very dynamic phenomenon, which requires the adoption of complex strategies:

[.. .] accommodation is to be seen as a multiply-organized and contextually complex set of alternatives, regularly available to communicators in face-to-face talk. It can function to index and achieve solidarity with or dissociation from a conversational partner, reciprocally and dynamically. (Giles et al. 1991: 2)

Relying on the studies mentioned above, this paper aims to examine the principal strategies employed by lecturers to explain the main specialised terms and technical concepts associated with the specific courses they are teaching, as well as those adopted to overcome the difficulties of comprehension experienced by their students. It is also our goal to highlight the cooperative work carried out by both learners and teachers in the explanation/comprehension of specific topics in order to facilitate the achievement of the teaching/learning objectives of the courses. Although the analysis of the data in our corpus will mainly be based on the taxonomy of metadiscursive and communicative strategies briefly listed above, when necessary, these will be integrated with any other practices found in further specific cases. The data will be categorised according to their main function, although in some cases more than one purpose could be attributed to the use of certain interactive strategies. In these cases the most prominent function (according to the context) will be identified and considered prevalent over the others.

\section{Explanatory strategies}

The analysis of the corpus shows that before introducing a new concept, the lecturer often checks the students' previous knowledge of it. He does so by asking specific questions about that topic. As can be seen in the following example, the lecturer then integrates the students' answer in order to expand his explanation of the concept being dealt with:

(1) L3: what is a theory?

S: it's a model

L3: it's a model to explain demonstrate something (.) a theory helps you to visualize how you observe things

As can be seen, this triadic form of interaction closely follows Sinclair and Coulthard's (1975) IRF pattern (IRF = Initiation - Response - Follow-up). When- 
ever the students reply giving the right explanation, the lecturer provides very positive feedback (emphasis added by means of underlining, as in the rest of the paper; see the appendix for transcription conventions):

(2) L2: who can tell me the difference between price and value?

S: price is like how much you pay for a product for a service (.) the value is the benefits that you get from the product

L2: perfect!

Sometimes the lecturer wants to focus the students' attention more clearly on the argumentative topic that he is introducing and thus, in order to highlight the grammatical subject of the question, he recurs to a grammatical device such as left dislocation:

(3) L3: and social account what is it? CSR is the politics and what is social account?

At times the lecturer refers to concepts that he thinks the students already possess by the use of the expression you know:

(4) L3: you know almost all the big multinational companies prepare a sustainability account

In introducing specialised terms the lecturer sometimes uses the inclusive pronoun we; in this way he aims to better socialise the students into the concepts he is explaining:

(5) L3: we can use these terms like SER as a way to describe corporate reporting process

Sometimes, in order to show that they have understood the concept explained by the lecturer, students answer his question giving a synonym, as in the following case concerning the French word chauviniste:

(6) L2: [...] for example the most important region for tourism is Île de eh Île de France but the french citizens are chauviniste you understand the term? it's proud of itself

S: very nationalistic

L2: yeah always the best of the world 
Particularly when dealing with theoretical aspects, the lecturer often finds it very useful to introduce some exemplifications in order to make his explanations more concrete. This is the case in the following quotation, where the lecturer is trying to differentiate between the concepts of principles and actions:

(7) L3: and so (.) be careful to distinguish principles and actions ... obviously it is a scandal if an important member of religion or a politician acts against the principles he says for people but (.) i was speaking about principles ... if you find a religion that says you can lie i offer you a dinner $<$ SS LAUGH> you know buddhist christian (.) nobody says you can lie

S: yes but they do

L3: you remember in the renaissance in some cases some bishops also the pope were not very fitting with the principles

Another strategy used to make an explanation more concrete is by illustrating it through the presentation of specific cases; sometimes these are presented in the first person singular as if they were part of the lecturer's experience:

(8) L2: so i have a lot of products (.) domestic sales are declining ... the example (.) $\mathrm{i}$ am working in the textile sector and chinese people or other people are selling products less expensive and somebody else is gaining my customers

The lecturer frequently checks whether the students are following by asking them if they have understood the concepts that he has explained. This is an interactional feature that has been shown to be typical of successful ELF lectures (Suviniitty 2012):

(9) L3: so we have also social accounts (.) voluntary (.) in which you account ... do you understand?

(10) L3: does it make sense to everyone?

If the speaker realises that what he is asking proves to be too difficult for his interlocutors, he decides to reformulate his question. In the following extract, for example, the lecturer starts asking for the definition of "merger", but when he realises that this may be too difficult for the students, he switches to the concept of acquisition:

(11) L2: [. . . ] for instance a merger or acquisition (.) well i must be careful what I ask you what is a merger? merger? ... eh easier an acquisition, what is 
an acquisition? that's when my firm buys another firm (.) a merger is if you have a business and I have a business we put our forces together but I'm the one boss

Sometimes the request for the explanation of a specific concept comes from the students themselves, as in the following case:

(12) L3: the second concept is eco-efficiency

S: what does it mean?

L3: the use of resources in a right way

The need for clarity is keenly felt by the lecturer, who expects that if students have difficulty in understanding a concept, they should ask a question. This attitude is frequently encouraged by the teacher, who seems very keen to build a relaxed and cooperative setting so that students can actively participate in the lesson and fully profit from it. In the following quotation, for example, the lecturer shows good sense of humour and a very supportive attitude towards his students:

(13) S: i have a question

L2: also today <LAUGH>

S: i always have a question

L2: this means that you are a wise person (.) questions are always very important... please

At times the lecturer appears not to be sure that all students have understood a specific concept - particularly when the interlocutors belong to a different culture - and so, in spite of a positive reply, he decides to provide further explanations. This is the case of the word pope in the following extract; to better convey the meaning of the word he is trying to explain, the lecturer recurs to gestures to imitate the Pope's hat:

(14) L1: [...] the pope <TO CHINESE STUDENT> you know what is the pope?

S: yes

L1: you know in Rome (.) this man <IMITATING THE POPE'S HAT> $<$ SS LAUGH >

The fact that the Chinese listener replies affirmatively does not necessarily imply that he has understood the meaning of the word pope. As this is an ELF situation, perhaps it would have been better for the lecturer to have used a more general expression such as the head of the Catholic church, thus avoiding a mistaken 
presupposition of shared cultural background. However, the lecturer is aware of the possibility of potentially different cultural backgrounds among the listeners and therefore he decides to accompany his explanation with a gesture to imitate the Pope's hat. This choice also has the added advantage of arousing laughter, thus creating a good atmosphere in class.

A further strategy adopted in order to make the meaning of a term clearer is translation. However, since the students come from different linguistic backgrounds, the lecturer tries to cope with their difficulty by using various equivalents in the languages he knows:

(15) L2: each year from two thousand eight the European Commission organises a prize

S: ah the last word is ... commission organises what exactly?

L2: a prize

S: ah

L2: a concours, a premio a competition

In this way the lecturer exploits his linguistic competence as a multilingual speaker by drawing on the range of languages in his repertoire in a skilful way, a strategy which has been observed also in other instances of ELF communication (Cogo 2009; Mauranen 2013).

\section{Metadiscursive strategies}

The analysis of the corpus shows the presence of both kinds of strategies pointed out by Aguilar Pérez and Arnò Macià (2002). Textual features are discussed below first.

\subsection{Textual}

\subsubsection{Frame markers}

The lecturers often adopt appropriate metadiscursive elements in order to shape their discourse and highlight their attitude, thus making their teaching objectives more explicit. The corpus examined here shows the use of several illocutionary markers, such as the verbs show, explain, introduce, review, or describe:

(16) L3: i will show you the sustainability account and other documents of one big company 
(17) L3: but i will explain you what is the difference because ethical code is very different from social accounting

(18) L3: today i will introduce you some reasonings about the problems to have a good social accounting

In doing this, the lecturer sometimes uses the inclusive first person plural pronoun we, which is meant to involve the students more closely into his teaching activity:

(19) L3: we will explore together what kind of requirements we must have to build a sustainability report

On other occasions the lecturer links his present teaching activity to a previous phase of the course in which a similar concept has been dealt with:

(20) L3: i told you on tuesday (.) in these hours i'm providing you more questions than answers I'm here to deconstruct your certitudes ok?

\subsubsection{Rhetorical questions}

Another way of organising one's own argumentative path is to start the explanation of a new concept by asking a rhetorical question, by means of which the lecturer raises an issue which he subsequently proceeds to illustrate. Here is an example found in the corpus:

(21) L3: in every country auditing of financial statement is compulsory by law (.) why is compulsory? to guarantee as much as possible (.) obviously if the company that is audited does not cheat a lot and put the auditor in the condition not to work

Rhetorical questions do not only serve an argumentative function, but they are often used to increase the degree of interactivity of the lecturer's explanations. For example, in the following quotation the use of you in the rhetorical question is meant to highlight the students' involvement:

(22) L2: in Ireland a lot of italian banking institutions open subsidiaries in Ireland (.) do you know why? because they are in the EU (.) we have the same currency we have the same law but the specific irish law allow to have less taxes on the capital gained 
These questions are not really audience oriented but rather content oriented (Thompson 1998), as no response is expected. As Björkman (2010: 87) has rightly asserted, rhetorical questions of this kind - although not meant to elicit direct feedback from the students - "add [.. . ] to the interactivity of the lecture and also serv[e] as signposts for the listener," as they lead students to focus their attention on a specific issue during the lecture. Here are two more examples of this teaching strategy:

(23) L1: [...] they can offer better interest rates for loans (.) you know what is a loan? when I give you money but I tell you you pay me back in ten years

(24) L2: [. . . ] what we call <WRITING ON BOARD $>$ win-win situation have you_is this notion known to you? win-win situation is_i give you something you give me something (.) we both win (,) it's possible (.) this should be the basic principle of cooperation

\subsubsection{Rephrasing}

When the concept is complex and the lecturer has the impression that his first explanation has not been understood completely, he usually recurs to a periphrasis, often introduced by the expression in other words:

(25) L3: if you want to envisage a real social accountability that produces change (.) we should extend the social accountability beyond the legal and regulation (.) in other words we should as well take into consideration the quasi-legal accountability

Besides its academic value, rephrasing also has an important interpersonal aspect as it enables the speaker to convey his message in a clearer way and therefore to establish a friendlier relationship with his interlocutor (Mauranen 2010).

Another way of facilitating comprehension is by reformulating the text whenever the speaker thinks the expression he has uttered may be too difficult for his interlocutors. This is the case, for example, in the following quotation in which the lecturer first uses the term physician and then he shifts to doctor subsequently specified as medical doctor:

(26) L1: [...] after seven hour a physician a doctor a medical doctor got a heart disease

At times the reformulation is expressed as an explicit paraphrase: 
(27) L2: [...] the brand normally has a slogan and Avis said a ci-_a fantastic slogan in marketing they said Avis (.) we try harder do you understand in english? we try harder (.) that means we do it better we do more for you

Particularly in the European Tourism Law lessons, the lecturer at times uses a few Latin words which he considers specialised terms to be learnt as part of his course. These terms would not be particularly difficult for the Italian students in his class as they are also used in many situations in their own native language. However, the lecturer presupposes that other students do not know Latin and therefore he accompanies the terms with an equivalent in English:

(28) L2: [...] what we call in latin res publica the state

(29) L2: [...] it's as always in commercial relations in do ut des (.) i give you something you give me something

(30) L2: this period coming from the day of publications and the date of enter into force according to a latin proverb is vacatio legis which means that we need a period to prepare all the juridical systems at this new legal order

Code switching in this case is used with the function of introducing a specific concept (Klimpfinger 2009).

\subsection{Interpersonal}

Besides textual features, also interpersonal strategies are prominent in the corpus collected. Indeed, examples of the various types mentioned by Aguilar Pérez and Arnò Macià (2002) have been found in the ELF interactions recorded in the "international" courses.

\subsubsection{Emphasising}

When the lecturer presents a concept as particularly relevant, he adds emphasis to his explanations. Various strategies used to achieve this effect have been found in the corpus. One - often adopted in academic courses (Björkman 2010) - is to use adjectives such as important, crucial, or essential, sometimes strengthened by the booster very and/or the attitudinal marker definitely: 
(31) L3: all stakeholders are important ... for a bank the treatment of investors is essential

(32) L2: it is definitely very important

Another way to increase emphasis is by strengthening the importance or difficulty of a concept by means of lexical repetition:

(33) L3: what is CSR? very very hard question

(34) L3: this is obviously in the world of the companies very very important

Repetition is also used to highlight the various items of a list. In the following quotation, the expression for example is inserted before each of the four marketing elements beginning with the letter "p":

(35) L2: for instance, people! for instance, public power! for instance, public opinion! for instance, PR!

To make his explanations more convincing, the lecturer often adds argumentative boosters such as the adverbial forms obviously or of course:

(36) L3: obviously when we speak about auditing we are usually thinking about external auditing because we also have internal auditing in (.) management accounting

(37) L3: for example the principles are well distinguished in two groups ... the most important is of course transparency

Another way to strengthen one's assertion explicitly is by using direct stance markers (Mortensen 2010, forthcoming; Pullin 2013), such as very positive adjectives included in exclamatory sentences:

(38) L2: the Brembo brakes are the number one in the world not only for the brand but because they supply all the formula 1 cars (.) unbelievable!

The importance of some specific concepts may be underlined by means of directives (Suviniitty 2012), i.e., direct speech acts requesting students to pay particular attention such as you have to, be careful, don't forget:

(39) value added is bigger than profit because it includes not only profit but also salaries ... and be careful if you speak about the cost of salaries (.) it is different in different countries 
To introduce the expression of a personal opinion, the speaker often uses a stance marker. In doing this, however, the lecturer clearly signals this as a subjective statement (e.g., in my opinion, I think) so as to distinguish it from the objective data and theories that he is presenting as part of his specialised course:

(40) L3: what is the real meritocracy? in my opinion to have a career only for your capacity and also to organize a society in which people can start the career not indicated by others

(41) L3: a company that does social action and does not respect these things i think it's worse because a company that does philanthropy and also accounting exploits employees and this philanthropy could cover this bad behaviour

The subjectivity of the lecturer's opinion is sometimes explicitly indicated by underlining the lack of assertiveness or by using downtoners such as the adverb only or the adjective modest:

(42) L3: this is my opinion, it is not sustained by any empirical research

(43) L3: and probably (.) it is only my opinion (.) after this case they published their social account of six hundred pages

(44) L2: and when we try to understand what is in the head of the customers this is more difficult ... and when the difference are not made by the machines but by people i think that (.) my modest opinion (.) this is what $\mathrm{i}$ prefer

\subsubsection{Inserting interactivity in the explanation}

In his explanations the lecturer often anticipates possible objections or comments that the students might want to raise so as to make his lessons more dialogic, as can be seen in the following examples:

(45) L3: the italian republic made another treaty in which eight per one thousand of your taxes (.) if you like (.) you can sign to give them to catholic church organisation (.) and also to other christian confessions ... the problem you say is that a part of this eight per one thousand goes to the state... what you say is the money that the state has (.) how is it used?

(46) L3: a report you will think is a report not a message 
Another way to make the text more dialogic is to anticipate the interlocutors' possible objections or comments by inserting direct speech:

(47) L3: if you say (.) i have to prepare social account because my competitors do it (.) you are free but if your competitors prepare it (.) you are forced to do it because of competition

Another sign of interactivity is the use of expressions intended to check interlocutors' comprehension and approval such as OK?:

(48) L3: so when we speak about any historical analysis always don't forget this is influenced by the biases of the historians (.) ok?

\section{Cooperative strategies}

When interacting with his students, the lecturer has a very cooperative attitude. This can be seen, in particular, when the student is not able to complete his/her sentence because of a certain lack of fluency. In this case, as soon as the lecturer understands the message - although partially formulated by the student - he completes the sentence adding the missing information:

(49) S: what (.) uh (.) if a company with religious ...

L3: a religious company is owned by people who are uh priests ... we have different situations

The same cooperative attitude can be seen when the lecturer integrates his students' questions. In the following quotation, for example, the lecturer notices that the student is not able to complete his explanation of where the car dealer is situated and so intervenes by making a suggestion:

(50) L2: and which is the official dealer?

S: we don't have (.) it's only in Milan (.) Auto Torino is a multibrand dealer but it has a lot of american cars and a big range of Chrysler models

L2: and where is it?

S: it is situated in Curno (.) ehm at the...

L2: near Esselunga?

S: no near Castorama

When difficulties of expression arise on the part of the lecturer, students often adopt some proactive measures and cooperative strategies (as in Mauranen 
2006b) in order to help avert problems of understanding and thus favour a successful achievement of communicative intention. This can be seen, for example, in those cases in which the Swiss lecturer has a problem in mentioning Italian place names. In these cases the Italian students attending the course complete or correct the names referred to:

(51) L1: [...] resort like Cortina d’Ampezzo or Ma-madonna del Cam-

SS: campiglio

L1: piglio

(52) L1: they have places where they operate eh business (.) business cities like Milano (.) also small ones where there is a business (.) i was eh yes is funny (.) i was in eh in italian place where where they produce prosecco very near to Venice (.) i cannot pronounce it unfortunately in exact (.) yes this i can i can Valdo-?

SS: Valdobbiadene

L1: yeah Valdobia-

SS: -dobbiadene

S1: dobiane dobiane eh i know

The recourse to cooperative strategies can be seen also in those cases in which the lecturer is not able to find the right word in English and directly appeals for assistance. In these cases the students help him by providing the word needed:

(53) L1: [...] how do you say ehm the phoque (.) this eh arctic animal (.) you see very nice animal eh

S: seal

L1: seal seal ah beautiful <SS LAUGH $>$

The lecturer's repetition of the word does not only imply his acquisition of the term, but also underlines the cooperative process established in class in the construction and sharing of new knowledge. Repetition is thus not only comprehension oriented but also interaction oriented (Lichtkoppler 2007) as it is meant to highlight participation and solidarity.

This spirit of cooperation is also present in those cases in which the lecturer is confused in explaining the meaning of an acronym, as is visible in the following extract referring to the concept of ICT:

(54) L1: [...] tour operators they have today (.) they largely use ITC ... ICT is obvious ICT 
S1: I don' know it

L1: you don't know? but you use it i'm sure

S1: ahh

L1: ITC (.) ICT

S2: information and communication technology

L1: information and communication technology yes

Cooperation is also shown when unplanned breaks are made in the lecture. In the following extract, for example, the lecturer is distracted by the late arrival of a student; the other students help him resume the previous teaching path:

(55) L2: <TO A STUDENT ENTERING THE ROOM> eh I'm talking about eh

S1: transport

L2: transport

S2: strategy for mobility

L2: and strategy for m-mobility (.) sustainable mobility yeah

S3: and requirement

L2: require-_eh a combination of action strategies

A cooperative attitude is also visible in many instances of utterance completion where students continue the lecturer's sentence by providing fitting words or specific technical terms. In many cases, the lecturer does not only repeat the term but also adds a positive remark so as to express his approval:

(56) L1: [...] we grow internally without buying another enterprise or without ehm I will say cooperation (.) you are becoming bigger and bigger and external growth is then contrary

S: acquisition

L1: acquisition and merger yes good

(57) L2: food, food is also in some destination is very complicated

S: water

L2: water of course, yes

In contrast, when the completion words suggested are not the ones expected, the lecturer corrects them by providing the right solution:

(58) L2: [...] probably you have travelled to a place (.) then this is a characteristic industry (.) those who organize travelling

S: travel agencies

L2: yes tour operators exactly 
In some cases students continue the lecturer's sentences by adding more examples or words to the list:

(59) L1: [...] current situation (.) we have a very advanced process of negotiation with Serbia ... Croatia ... there will be in more time Albania ... Montenegro

S: and Turkey

(60) L2: [...] urban centre became most attractive because young people that study in this university Heidelberg Aix-en-provence

S1: Saint Andrews

S2: Urbino

The corpus sometimes reveals turns that show great difficulty in communication, in which however the lecturer tries to keep the interaction going with his students. In the following extract, for example, the student does not catch the metaphorical usage of the expression feel at home as he thinks that reference is made to his own home, which creates serious misunderstanding and confusion in the last part of the exchange clearly indicated by the question "What does that mean?" uttered by the lecturer:

(61) L1: Air Bangladesh exist?

S: yes it exists

L1: what is the exact name?

S: Bangladesh Biman

L1: Bangladesh what?

S: Bangladesh Biman (.) B-I-M-A-N

L1: BIN what does that mean?

S: biman means ah like a flying bird

L1: flying bird?

S: flying bird ah

L1: flying bird <LAUGHS > ah in Bangladesh flying bird

S: $\quad$ yeah $<$ SS LAUGH>

L1: that's nice $<$ SS LAUGH $>$ but you feel at home when you fly with Bangladesh Biman?

S: in my home?

L1: yeah you feel at home if you fly this company?

$\mathrm{S}$ : oh is no more modern

L1: it's not modern?

S: yes 


\section{L1: what does that mean? <LAUGHS>}

S: okay it's because it's not a familiar real airline sector

The lecturer uses a formulaic expression in a native-like way, but its figurative meaning is unknown to the student, who instead interprets the utterance only in a literal sense, which is a clear case of "unilateral idiomaticity" (Seidlhofer 2004: 220). This discrepancy in processing leads to misunderstanding between the speakers. Indeed, the use of formulaic language can be quite problematic in ELF contexts as it requires shared background knowledge and conceptual fluency. As ELF speakers often do not have this experience and competence, they therefore try to cope with the communicative task at hand by using the linguistic code as directly as possible. As Kecskes rightly asserts:

ELF data show that non-native speakers use the linguistic code itself as a common ground rather than the socio-cultural background knowledge that differs significantly with each participant. This strong reliance on the linguistic code results in the priority of literal meaning over non-literal, figurative language and formulaic language. [.. .] This is where a significant difference between native speaker and lingua franca communication should be noted. While for native speakers either (or both) literal and non-literal meaning can be the most salient meaning, non-native speakers usually consider literal meaning as the most salient meaning of an expression in most situations. If that does not work out they make the necessary modifications by negotiating meaning. (Kecskes 2007: 204-205)

Another lecturer in our corpus seems to be aware of the fact that idioms are culture bound, as he often checks that the students understand them properly and in some cases he asks them to give their own local rendering of the same concept, as can be seen in the following case:

(62) L3: what is the elephant in the bedroom?

S: it means something very very big

L3: so it's a sort of contradiction ... how do you say this in italian?

$\mathrm{S}$ : $\quad$ un elefante in una cinquecento

The successful realisation of communicative interaction is the norm in the corpus examined here. Indeed, the cases in which a "let it pass" strategy is adopted are rare, which means that lecturers are always keen on explaining concepts that have not been grasped or correcting students' formulations that are not appropriate. The few occurrences that have been found concern minor points that have not been cleared completely but which are not considered so important as to require further negotiation of meaning. One example is the quotation below, in which the discrepancy of the university systems from which the students come 
does not allow a clear specification of the year the students are in; noticing the difficulty of finding out this information, the lecturer in the end accepts their vague assertion that they are Erasmus students:

(63) L1: also you first year?

S1: ehm

S2: we are third_i'm third year

L1: ah

S1: but there are four years

L1: but here? you don't know exactly which level?

S2: Erasmus (.) we are Erasmus

L1: you are Erasmus okay good hm

\section{Conclusion}

The analysis carried out in this paper has highlighted some of the strategies employed by lecturers to explain the main specialised terms and technical concepts from the specific courses they are teaching, as well as those adopted to overcome the difficulties of comprehension experienced by their students. Apart from various teaching techniques pointed out in previous studies on ELF (particularly those based on large corpora such as ELFA and VOICE, cf. Mauranen 2006a; Mauranen et al. 2010; Seidlhofer 2010, 2011; Smit 2010), the data investigated have shown a frequent use of interactive strategies, which are adopted by lecturers in order to make the comprehension of their lectures easier. Their aim is to make their lessons as participative as possible, as shown by the continuous check of their interlocutors' comprehension of the various concepts introduced in their courses and their availability in answering questions and providing the explanations required. Moreover, by increasing interactivity, they succeed in making their lectures more dialogic than monologic, creating opportunities for the negotiation of meaning and clarification. Indeed, our analysis has confirmed the results of previous studies (e.g., Miller 2009; Hellekjær 2010; Suviniitty 2012) which show that the most comprehensible lectures (as demonstrated by student assessment) were the ones where the lecturer made use of a number of different interactive features. As previous studies have pointed out (Chiang and Dunkel 1992; Klaassen and Bos 2010), lecturers that are highly competent in English do not necessarily give good lectures unless they make frequent use of communicationenhancing pragmatic strategies.

Of course, some of the communicative strategies highlighted here are not unknown in non-ELF lectures. However, some presuppose a multilingual 
environment and therefore tend to be more typical of an ELF situation, in which both lecturers and students do not fully master the foreign language that they are using. This fact explains a considerable presence of cooperative strategies, adopted by both learners and teachers to facilitate the achievement of the teaching/ learning objectives of the courses. These strategies reveal the interlocutors' willingness to make adjustments and accommodations in order to favour mutual intelligibility and successful linguistic communication. This continuous communicative interaction creates a feeling of strong collaboration within the class, which is deemed particularly important for a successful progress of the course. Students show great willingness to cooperate with their tutors in accomplishing the communicative purpose of the interactions in which they are involved.

We are aware that ELF studies have sometimes been criticised for overstating the claim of collaboration/mutual support and we agree with those that have remarked that this cooperative spirit does not characterise all ELF interaction. As Seidelhofer (2004) aptly remarks, work on ELF pragmatics is still very much in its initial phase, and the findings available to date may be a function of the type and purpose of the interactions investigated. It is true, however, that the data presented here highlight a high degree of cooperativeness on both sides when they interact among themselves so as to favour a successful outcome of the specialised communication in which they are involved. Their awareness of not being native speakers seems to create a higher motivation in their adoption of supportive moves than is commonly noticed in settings only involving native speakers. Indeed, proactive (Mauranen 2006b; Kaur 2009), interactive (Björkman 2010; Suviniitty 2012), and explicitation (Mauranen 2007) strategies have been found to enhance both communication and learning in ELF. As a result, the adoption of these strategies enables the interlocutors to accomplish their communicative purposes and to achieve the teaching objectives of their specialised courses.

\section{Appendix: transcription conventions}

L1 Lecturer of European Tourism Law (Swiss, German native speaker)

L2 Lecturer of Marketing Management (Italian)

L3 Lecturer of Business Ethics and Social Accounting (Italian)

S student

SS students

- false start

(.) short pause (1-2 seconds)

... longer pause (3-4 seconds) 
Acknowledgment: I thank Dr Larissa D’Angelo (University of Bergamo) for organising and overlooking the recording and transcription of the various teaching activities.

\section{References}

Aguilar Pérez, Marta \& Elisabeth Arnò Macià. 2002. Metadiscourse in lecture comprehension: Does it really help foreign language learners? Atlantis 24(2). 7-20.

Björkman, Beyza. 2008a. English as the lingua franca of engineering: The morphosyntax of academic speech events. Nordic Journal of English Studies 7(3). 103-122.

Björkman, Beyza. 2008b. "So where we are": Spoken lingua franca English at a Swedish technical university. English Today 24(2). 11-17.

Björkman, Beyza. 2009. English as a lingua franca at a Swedish technical university: An effective medium? In Melinda Whong (ed.), Proceedings of the annual BALEAP conference: EAP in a globalising world: English as an academic lingua franca, 11-19. Reading: Garnet.

Björkman, Beyza. 2010. "So you think you can ELF”: English as a lingua franca as the medium of instruction. Hermes - Journal of Language and Communication Studies 45. 77-97.

Cai, Deborah \& Jose Rodriguez. 1997. Adjusting to cultural differences: The intercultural adaptation model. Intercultural Communication Studies 6(2). 31-42.

Chiang, Chung Shing \& Patricia Dunkel. 1992. The effect of speech modification, prior knowledge, and listening proficiency on EFL lecture learning. TESOL Quarterly 26(2). 345-374.

Cogo, Alessia. 2009. Accommodating difference in ELF conversations: A study of pragmatic strategies. In Anna Mauranen \& Elina Ranta (eds), English as a lingua franca: Studies and findings, 254-273. Newcastle: Cambridge Scholars.

Crismore, Avon. 1989. Talking with readers. Metadiscourse as rhetorical act. Frankfurt: Peter Lang.

Firth, Alan. 1996. The discursive accomplishment of normality: On "lingua franca" English and conversation analysis. Journal of Pragmatics 26(2). 237-259.

Giles, Howard \& Tania Ogay. 2007. Communication accommodation theory. In Bryan Whaley \& Wendy Samter (eds), Explaining communication: Contemporary theories and exemplars, 293-310. Mahwah, NJ: Lawrence Erlbaum.

Giles, Howard, Nikolas Coupland \& Justine Coupland. 1991. Accommodation theory: Communication, context, and consequence. In Howard Giles, Justine Coupland \& Nikolas Coupland (eds), Contexts of accommodation: Developments in applied sociolinguistics, 1-68. Cambridge: Cambridge University Press.

Hellekjær, Glenn Ole. 2010. Lecture comprehension in English-medium higher education. HERMES - Journal of Language and Communication Studies 45. 11-34.

Hyland, Ken. 1998. Persuasion and context: The pragmatics of academic metadiscourse. Journal of Pragmatics 30. 437-455.

Hyland, Ken. 1999. Talking to students: Metadiscourse in introductory coursebooks. English for Specific Purposes 18(1). 3-26.

Jenkins, Jennifer. 2000. The phonology of English as an international language. Oxford: Oxford University Press. 
Kaur, Jagdish. 2009. Pre-empting problems of understanding in English as a lingua franca. In Anna Mauranen \& Elina Ranta (eds), English as a lingua franca: Studies and findings, 107-124. Newcastle: Cambridge Scholars.

Kecskes, Istvan. 2007. Formulaic language in English lingua franca. In Istvan Kecskes \& Laurence Horn (eds), Explorations in pragmatics: Linguistic, cognitive and intercultural aspects, 191-218. Berlin \& New York: Mouton de Gruyter.

Klaassen, Renata \& Madeleine Bos. 2010. English language screening for scientific staff at Delft University of Technology. HERMES - Journal of Language and Communication Studies 45. 61-76.

Klimpfinger, Theresa. 2009. "She's mixing the two languages together" - Forms and functions of code-switching in English as a lingua franca. In Anna Mauranen \& Elina Ranta (eds), English as a lingua franca: Studies and findings, 348-371. Newcastle: Cambridge Scholars.

Leznyák, Agnes. 2002. From chaos to the smallest common denominator. Topic management in English lingua franca communication. In Karlfried Knapp \& Christiane Meierkord (eds), Lingua franca communication, 163-193. Frankfurt: Peter Lang.

Lichtkoppler, Julia. 2007. "Male. Male." - "Male?" - "The sex is male.” The role of repetition in English as a lingua franca conversations. VIEWS 106(1). 39-65.

Mauranen, Anna. 1993. Contrastive ESP rhetoric: Metatexts in Finnish-English economic texts. English for Specific Purposes 12(1). 3-22.

Mauranen, Anna. 2003. The corpus of English as lingua franca in academic settings. TESOL Quarterly 37(3). 513-527.

Mauranen, Anna. 2006a. A rich domain of ELF - The ELFA corpus of academic discourse. Nordic Journal of English Studies 5(2). 145-159.

Mauranen, Anna. 2006b. Signalling and preventing misunderstanding in English as lingua franca communication. International Journal of Sociology of Language 177. 123-150.

Mauranen, Anna. 2007. Hybrid voices: English as the Lingua Franca of academics. In Kjersti Fløttum, Trine Dahl \& Torodd Kinn (eds), Language and discipline perspectives on academic discourse, 244-259. Newcastle: Cambridge Scholars.

Mauranen, Anna. 2010. Features of English as a lingua franca in academia. Helsinki English Studies 6. 6-28.

Mauranen, Anna. 2012. Exploring ELF: Academic English shaped by non-native speakers. Cambridge: Cambridge University Press.

Mauranen, Anna. 2013. Lingua franca discourse in academic contexts: Shaped by complexity. In John Flowerdew (ed.), Discourse in context, 225-246. London: Bloomsbury Academic.

Mauranen, Anna, Niina Hynninen \& Elina Ranta. 2010. English as an academic lingua franca: The ELFA project. English for Specific Purposes 29(3). 183-190.

Miller, Lindsay. 2009. Engineering lectures in a second language: What factors facilitate students' listening comprehension? Asian EFL Journal 11(2). 8-30.

Mortensen, Janus. 2010. Epistemic stance marking in the use of English as a lingua franca. Roskilde: Cardiff University and Roskilde University doctoral dissertation.

Mortensen, Janus. Forthcoming. Subjectivity and intersubjectivity as aspects of epistemic stance marking. In Nicole Baumgarten, Inke Du Bois \& Juliane House (eds), Subjectivity in language and discourse, 227-244. Leiden: Brill.

Pennebaker, James, Matthias Mehl \& Kate Niederhoffer. 2003. Psychological aspects of natural language use: Our words, our selves. Annual Review of Psychology 54. 547-577. 
Pullin, Patricia. 2013. Achieving “comity": The role of linguistic stance in business English as a lingua franca (BELF) meetings. JELF 2(1). 1-23.

Ranta, Elina. 2006. The "attractive" progressive - Why use the -ing form in English as a lingua franca? Nordic Journal of English Studies 5(2). 95-116.

Ranta, Elina. 2009. Syntactic features in spoken ELF - Learner language or spoken grammar? In Anna Mauranen \& Elina Ranta (eds), English as a lingua franca: Studies and findings, 84-106. Newcastle: Cambridge Scholars.

Seidlhofer, Barbara. 2001. Closing a conceptual gap: The case for a description of English as a lingua franca. International Journal of Applied Linguistics 11(2). 133-158.

Seidlhofer, Barbara. 2004. Research perspectives on teaching English as a Lingua Franca. Annual Review of Applied Linguistics 24. 209-239.

Seidlhofer, Barbara. 2010. Giving VOICE to English as a lingua franca. In Roberta Facchinetti, David Crystal \& Barbara Seidlhofer (eds), From international to local English - And back again, 147-163. Bern: Peter Lang.

Seidlhofer, Barbara. 2011. Understanding English as a Lingua Franca. Oxford: Oxford University Press.

Sinclair, John \& Malcolm Coulthard. 1975. Towards an analysis of discourse. Oxford: Oxford University Press.

Smit, Ute. 2009. Emic evaluations and interactive processes in a classroom community. In Anna Mauranen \& Elina Ranta (eds), English as a lingua franca: Studies and findings, 200-225. Newcastle: Cambridge Scholars.

Smit, Ute. 2010. English as a lingua franca in higher education: A longitudinal study of classroom discourse. Berlin \& New York: Mouton de Gruyter.

Smit, Ute \& Emma Dafouz (eds). 2012. Integrating content and language instruction in higher education. Gaining insights from English-medium instruction at European universities. AlLA Review 25. Amsterdam \& Philadelphia: John Benjamins.

Suviniitty, Jaana. 2010. Lecturers' questions and student perception of lecture comprehension. Hensinki English Studies 6. 44-57.

Suviniitty, Jaana. 2012. Lectures in English as a lingua franca: Interactional features. Helsinki: University of Helsinki doctoral dissertation.

Thompson, Susan. 1998. Why ask questions in monologue? Language choices at work in scientific and linguistic talk. In Susan Hunston (ed.), Language at work, 137-150.

Clevedon: BAAL/Multilingual Matters.

\section{Bionote}

Maurizio Gotti is Professor of English Language and Translation at the University of Bergamo. His main research areas are English syntax, English lexicology, and the features and origins of specialised discourse, both in a synchronic and diachronic perspective. He is a member of the Editorial Board of national and international journals, and edits the Linguistic Insights series for Peter Lang. 